\title{
Immediate Dental Implants Placed in Fresh Extraction Socket for Type II Diabetic Patient: 2-Case Report
}

\author{
${ }^{1}$ Kadkhodazadeh Mahdi, ${ }^{2}$ Torkzaban Parviz, ${ }^{1}$ Mollaverdi Fatemeh, \\ ${ }^{3}$ Robati Maryam and ${ }^{4}$ Yoosefimanesh Hojjat \\ ${ }^{1}$ Department of Periodontics, Dental School, Shahid Beheshti University of Medical Sciences, Iran \\ ${ }^{2}$ Department of Periodontics, Dental School, Hamadan University of Medical Sciences, Iran \\ ${ }^{3}$ Department of Oral Medicine, ${ }^{4}$ Department of Periodontics, Dental School, \\ Ahvaz University of Medical Sciences, Iran
}

\begin{abstract}
The use of dental implants as an anchor has become a standard effective treatment modality to restore missing teeth and maxillofacial defects. However, the application of titanium dental implants is still limited because of various risk factors including host bone quality and quantity, smoking, age and systemic conditions. The researchers presents two case reports of immediate dental implants placed in fresh extraction socket for type II diabetic patient. After a 12-month follow-up period, all implants were integrated.
\end{abstract}

Key words: Dantal problem, patients, risk factors, mature bone, plasma glucose, Iran

\section{INTRODUCTION}

It has been proven that titanium is a biocompatible material and the use of endosseous titanium implants as an anchor has become a standard effective treatment modality to restore missing teeth and maxillofacial defects (Hasegawa et al., 2008). However, the application of implants is still limited because of various risk factors, including host bone quality and quantity (Van Steenberghe et al., 2002) smoking (Kan et al., 2002) age (Takeshita et al., 1997) and systemic conditions (Ozawa et al., 2002). Among the systemic conditions, diabetes mellitus is a major metabolic disease that significantly affects bone metabolic potential (Hasegawa et al., 2008).

For a long time, diabetic patients were denied implant therapy because of their increased susceptibility to infection, delayed wound healing and microvascular complications (Kadkhodazadeh et al., 2006; Tawil et al., 2008). The two major types of diabetes are type 1 (formerly known as insulin-dependent diabetes) and type 2 (formerly called "non-insulin-dependent diabetes). Over the past decade, the medical management of diabetes has changed significantly in an effort to minimize the debilitating complications associated with this disease. (DCCT Research Group, 1993; UKPDS, 1998). Patients are more tightly managing their blood glucose levels (glycemia) through diet oral agents and insulin therapy (Mealey, 1998).
Fluctuations in glucose level are very frequent and self-monitoring of plasma glucose is not commonplace. The effect of plasma glucose fluctuations on implant survival and the maintenance of osseointegration remain unclear (Tawil et al., 2008).

The primary test used to assess glycemic control in a known diabetic individual is the glycosylated (or glycated) Hematogolobin ( $\mathrm{Hb}$ ) assay.

Two different tests are available, the HbAl and the HbAlc assay; also HbAlc is used more often. This assay reflects blood glucose concentrations over the preceding 6-8 weeks and may provide an indication of the potential response to periodontal therapy. Patients with relatively well-controlled diabetes ( $\mathrm{Hb} \mathrm{Al},<8 \%$ ) usually respond to therapy in a manner similar to non-diabetic (Christgau et al., 1998; Tervonen and Karjalainen, 1997; Westfelt et al., 1996) .

Poorly controlled patients ( $\mathrm{Hb}$ non-diabetics $>10 \%$ ) often have a poor response to treatment with more postoperative complications and less favorable long-term results (Mealey, 1999). When possible, an HbAlc of $<10 \%$ should be established before surgical treatment is performed. If the patient has poor glycemic control and surgery is absolutely needed, prophylactic antibiotics may be given; penicillins are most often used for this purpose. In this study, the researchers presents two case reports of immediate dental implants placed in fresh extraction socket for type II diabetic patient. After a 12 month follow-up period, all implants were integrated.

Corresponding Author: Hojjat Yoosefimanesh, Department of Periodontics, Dental School, Ahvaz University of Medical Sciences, Iran 


\section{MATERIALS AND METHODS}

Patient profile: A 49 years old man and a 52 years old woman (both type-2 diabetic) were referred to the Implant Department of Dental School, Hamadan University of Medical Sciences for prosthetic rehabilitation using dental implants. At last years of ages, the patients had lost some teeth and were using a conventional partial denture. They were having a mean per-operative $\mathrm{HbAlc}$ level of 7.2 and $7.6 \%$ and compliant with a maintenance program. She was taking comadin and metformin. Also one of them (case 2) have a pace maker. The patients required a tow-tooth extraction for root fractures and caries. Implants were positioned immediately after tooth extraction and were loaded after 6 months.

Surgical procedure: The patients received $2 \mathrm{~g}$ amoxicillin $1 \mathrm{~h}$ prior to surgery and $1 \mathrm{~g}$ twice a day for a week after surgical procedure. About $1 \mathrm{~min}$ prior to surgery they rinsed with $0.12 \%$ chlorhexidine gluconate for $1 \mathrm{~min}$ (Fig. 1). Surgery was performed under local anesthesia (optocaine $20 \mathrm{mg} \mathrm{mL}^{-1}$ with adrenaline $1: 80,000$ ). The
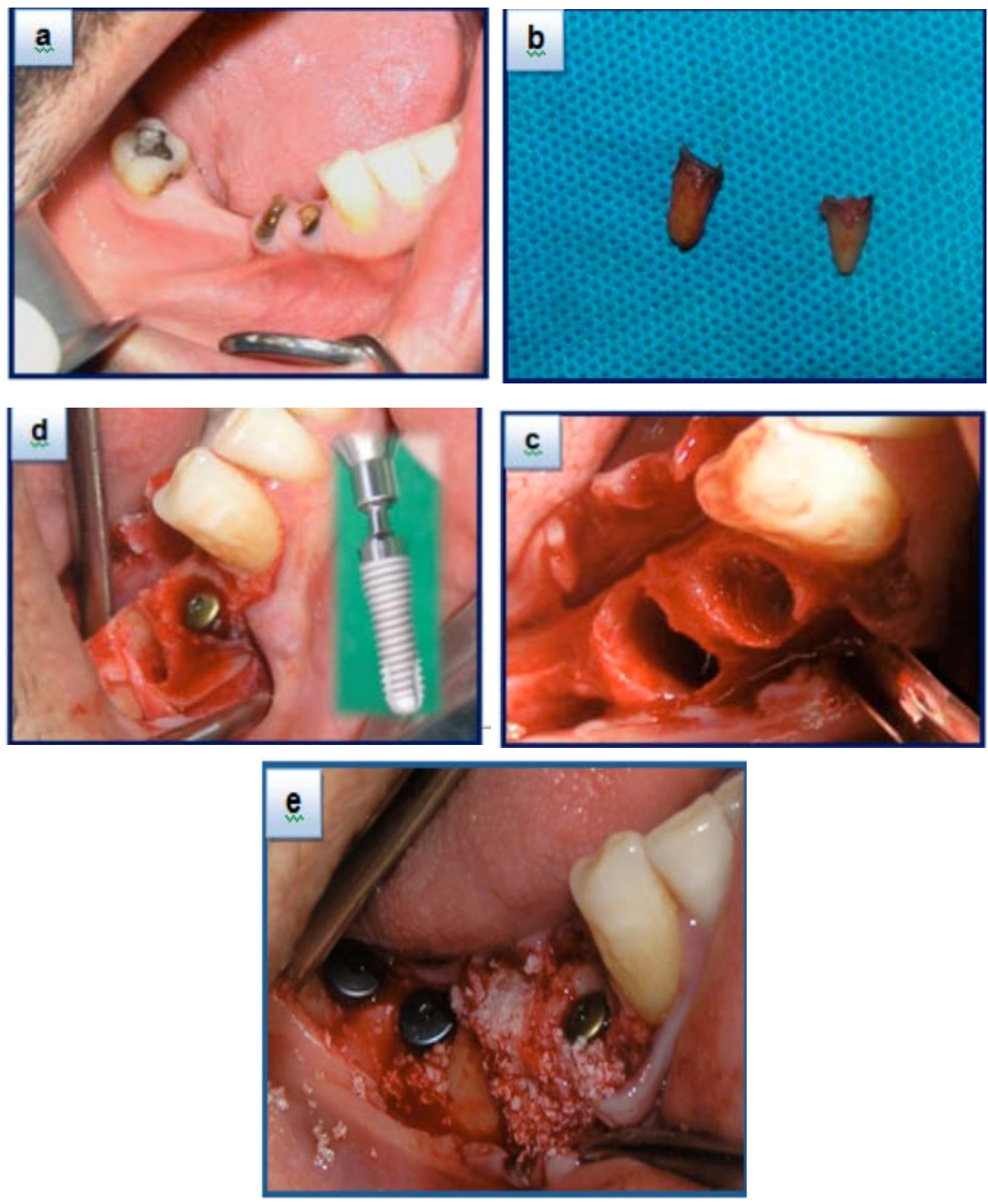

Fig. 1: Surgical procedure; a) pre-operative appearance; b) extracted roots; c) intraoral view of extraction sockets; $d$ and e implant placement 

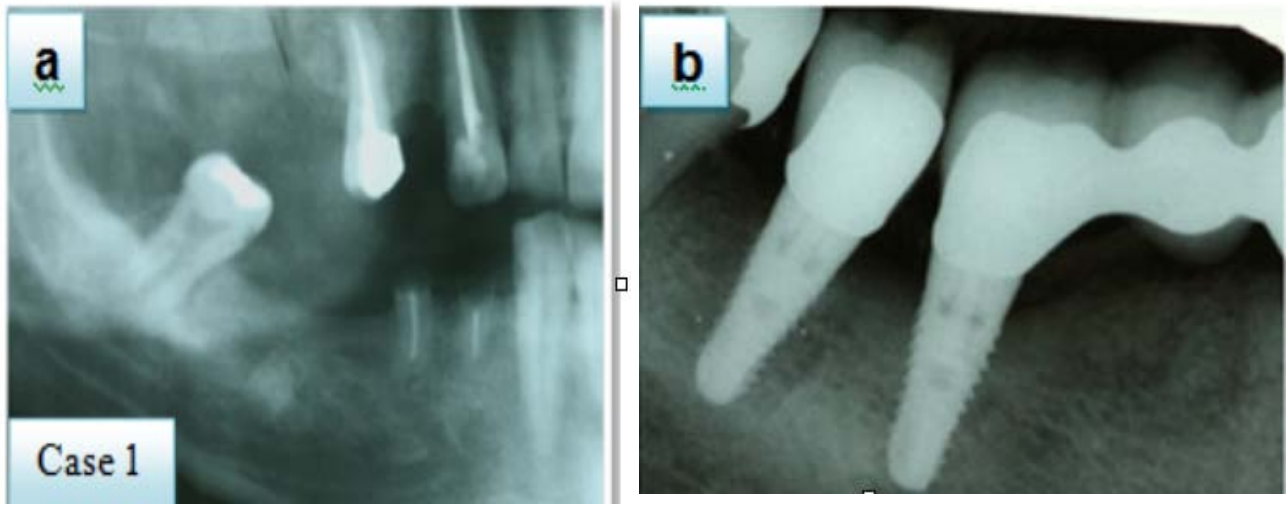

Fig. 2: a) Pre-operative radiographic appearance; b) Radiographic appearance at 12 months post-operatively

mucoperiosteal flap was raised with a sulcular/crestal incision without vertical releasing incisions.

Case 1: Mandibular first and second premolar were autromatic extracted and one implant (diameter of $3.5 \mathrm{~mm}$ and length of $12.5 \mathrm{~mm}$, SPI; Switzerland) was placed in the fresh socket of mandibular right first premolar immediately and two implants (diameter of $4.5 \mathrm{~mm}$ and length of $11 \mathrm{~mm}$, SPI; Switzerland) were placed in right first and 2nd molars regions for a 49 years old man (type-2 diabetic).

Case 2: Two implants (had a diameter of 3.5, $4.5 \mathrm{~mm}$ and length of 11, $12.5 \mathrm{~mm}$, SPI; Switzerland) were placed in the fresh socket of maxillary lateral incisor and canine (esthetic zone) immediately. Care was taken to maintain the integrity of the socket and buccal flaps were avoided. A periodontal probe was used to verify the integrity of the 4 walls of the fresh sockets. The implant site was prepared with a standard drill following the palatal bony walls as a guide and the apical portion of the implant was always placed at least $4 \mathrm{~mm}$ beyond the root apex; no countersinking was used. The coronal margin of the implant was located at the buccal level of the bone crest.

The quality of alveolar bone was determined during surgery for each site and was predominantly classified as type 2 or 3, according to Lekholm and Zarb (1985) classification. Implants were performed with an implant stability quotient (ISQ>60) and implant insertion torque $(>25 \mathrm{~N} / \mathrm{cm})$.

Fenestration of the residual bony walls was treated by Bio-oss (Geistlich Biomaterials, Wolhusen, Switzerland) and covered with a collagen barrier membrane (Bio-Gide; GeistlichBiomaterials, Switzerland). No decortication was done.

Primary, tension-free soft tissue closure was achieved by means of a split-thickness flap and interrupted sutures. The flap sutures were removed 12 days post-operatively.
The site was allowed to heal for 6 months. Chlorhexidine mouthwash was prescribed twice daily for 15 days following surgery.

Uncovering: About 6 mounts after implants placement, 2nd surgery (punch technique) was performed and gingival formers attached to them.

Prosthetic protocol: After 1 week, single-tooth, temporary prefabricated acrylic resin crowns were performed, adapted with acrylic resin along margins of the temporary abutment and fit with temporary cement (Temp Bond; Kerr Manufacturing, Romulus, MI). All temporary crowns were in full contact in centric occlusion. The patient followed a soft diet for 2 months.

Follow-up: The following clinical parameters were checked: pain, occlusion, prosthesis mobility and plaque and bleeding indices. Success criteria for implant survival were presence of implant stability, absence of radiolucent zone around the implants, no mucosal suppuration and no pain.

Radiographic examination: Intraoral radiographic examinations were made at baseline, 6 and 12 months after implant placement (Fig. 2). A radiologist measured the changes in marginal bone height over time. The marginal bone level was measured from the reference point (the most coronal portion of the implant in contact with the bone) to the point where the bone tissue met the implant surface at the mesial and distal sites.

Esthetic assessments: Esthetics were subjectively evaluated by trained dental professionals based on smile form, tooth structure, incisal edge, surface contours, line angles, contact area, embrasure form, surface texture and color and tissue contour (Fig. 3). 


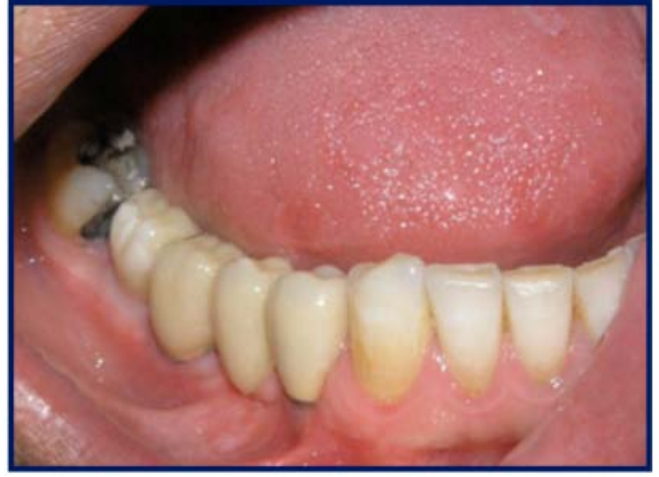

Fig. 3: Final restoration

\section{RESULTS AND DISCUSSION}

After a 12 months follow-up period, all implants were integrated. They had no pain, suppuration, redness and increasing bone loss. The mean of mesial bone loss of $1.03 \pm 0.22 \mathrm{~mm}$ and a mean distal bone loss of $1.15 \pm 0.31 \mathrm{~mm}$. Overall, the esthetic results were determined to be very good to excellent by a subjective assessment of the patients and clinicians.

Gomez-Roman et al. (1997) reported a 99.4\% success rate for 164 implants placed in mature bone, versus $97.1 \%$ for 86 immediate implants; these implants were of variable lengths and diameters and were positioned in the maxilla or mandible. In contrast, in these cases, the success rate for implants in mature bone and in postextraction bone was $100 \%$. Rosenquist and Grenthe (1996) placed 109 immediate implants for which they reported a success rate of $93.6 \%$. In addition to this study, a number of researchers have reported $100 \%$ success when placing immediate implants, such as Lang et al. (1994), placed 16 postextraction implants by Bragger et al. (1996), placed 28 implants in 21 patients by Yukna (1991) whose study included 14 implants in 14 patients by Goldstein et al. (2002) and with 38 immediate implants in 47 patients by Penarrocha-Diago et al. (2008).

On the other hand, according to the recommendations of the American Diabetes Association, HbAlc must be monitored twice a year but should be monitored more frequently if glycemic control is inadequate and the patient must self-monitor his glucose level daily, although the optimal frequency is not clearly defined.

For a long time, diabetic patients were denied implant therapy because of their increased susceptibility to infection, delayed wound healing and microvascular complications (McMahon and Bristrian, 1995; Pearl and Kanat, 1988). No results of clinical significance on advanced implant therapy in the diabetic patients were

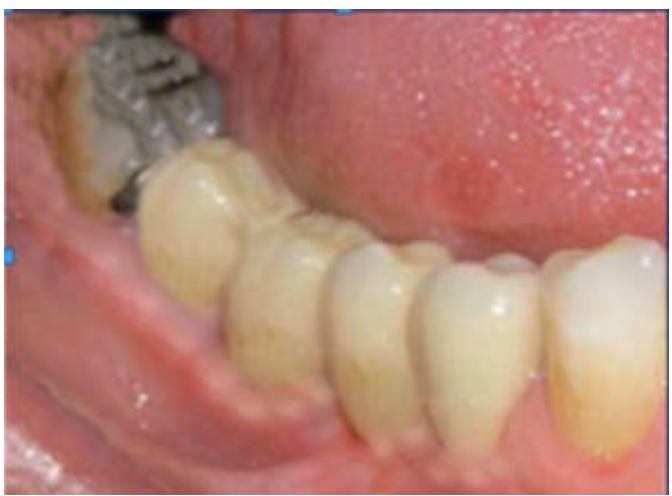

Fig. 4: Final restoration after 12 months

reported (Tawil et al., 2008). Diabetic parameters were mentioned in 2 studies (Kapur et al., 1998; Olson et al., 2000) and peri-implant bone loss was reported in 2 studies (Kapur et al., 1998; Peled et al., 2003). Two studies (Kapur et al., 1998; Morris et al., 2000) had a control group.

Although, all the reports underlined the importance of the control of the diabetic condition before any implant treatment is considered, no upper limits for hyperglycemia or $\mathrm{HbAlc}$ values were proposed either perioperatively or post-operatively to indicate implant therapy and safely maintain long-term implant stability. Olson et al. (2000) found no association between the levels of diabetic control and implant failure, despite an elevated $\mathrm{HbAlc}$ level in more $50 \%$ of the treated patients in the perioperative period (Fig. 4).

No failures were reported by Kapur et al. (1998) in cases of implant-supported overdentures, despite relatively elevated $\mathrm{HbAlc}$ values $(>9 \%)$ in the operative period and no statistically significant differences in the success rate between the insulin-treated and non-insulintreated patients were found. Absolute and constant control of plasma glucose level is elusive in most diabetic patients (Hanefeld and Temelkova-Kurktschiev, 2002; Tawil et al., 2008).

However, diabetic duration and overall diabetes control and their effect on cell function and vascular damage have to be accounted for, for a full evaluation of the patient profile (Bagdade et al., 1974; Jeffcoate, 2004). The risk of complications increases with the duration of hyperglycemia through the production of advanced glycation end-products that irreversibly accumulate on long-lived vessel walls, cause micro and macro-vascular complications and alter the phenotype of many cells (i.e., macrophages, polymorphonuclear cells, fibroblasts and endothelial cells) which causes increased susceptibility to infection, vascular changes and impaired healing (Brownlee et al., 1988). Within the limits of this study, the 
results showed that immediate implants placed in fresh extraction sockets for fairly to good control diabetic patient showed no complications after one year of follow-up.

\section{CONCLUSION}

The placement of implants in recent extraction sites (for fairly to good control diabetic patient) has been shown to achieve similar results to implants placed in healed mature bone after 12 months of follow-up within the limitations of these cases.

\section{REFERENCES}

Bagdade, J.D., R.K. Root and R.J. Bulger, 1974. Impaired leukocyte function in patients with poorly controlled diabetes. Diabetes, 23: 9-15.

Bragger, U., C.H.F. Hammerle and N.P. Lang, 1996. Immediate transmucosal implants using the principle of guided tissue regeneration (GTR). II. A crosssectional study comparing the clinical outcome one year after immediate to standard implant placement. Clin. Oral Implants Res., 7: 268-276.

Brownlee, M., A. Cerami and H. Vlassara, 1988. Advanced glycosylation end products in tissue and the biochemical basis on diabetic complications. New Eng1. J. Med., 318: 1315-1321.

Christgau, M., K.D. Palitzsch, G. Schmalz, U. Kreiner and S. Frenzel, 1998. Healing response to non-surgical periodontal therapy in patients with diabetes mellitus: Clinical, microbiological and immunological results. J. Clin. Periodontol., 25: 112-124.

DCCT Research Group, 1993. The effect of intensive diabetes treatment on the development and progression of long-term complications in insulin-dependent diabetes mellitus: The diabetes control and complications trial. New Engl. J. Med., 329: $977-986$.

Goldstein, M., B.D. Boyan and Z. Schwartz, 2002. The palatal advanced flap: A pedicle flap for primary coverage of immediately placed implants. Clin. Oral Implants Res., 13: 644-650.

Gomez-Roman, G., W. Schulte, B. D'Hoedt and D. AxmanKrcmar, 1997. The frialit-2 implant system: Five-year clinical experience in single tooth and immediately postextraction applications. Int. J. Oral Maxillofac Implants, 12: 299-309.

Hanefeld, M. and T. Temelkova-Kurktschiev, 2002. Control of post-prandial hyperglycemia. An essential part of good diabetes treatment and prevention of cardiovascular complications. Nutr. Metab. Cardiovascular Dis., 12: 98-107.
Hasegawa, H., S. Ozawa, K. Hashimoto, T. Takeichi and T. Ogawa, 2008. Type 2 diabetes impairs implant osseointegration capacity in rats. Int. J. Oral Maxillofac Implants, 23: 237-246.

Jeffcoate, S.L., 2004. Diabetes control and complications: The role of glycated haemoglobin, 25 years on. Diabet. Med., 21: 657-665.

Kadkhodazadeh, M., F. Mollaverdi and S.H. Ahmadpoor, 2006. Effect of demineralized bone matrix implantation on repair of alveolar socket of diabetic rats (type I). J. Clin. Periodontol., 33: 179-179.

Kan, J.Y., K. Rungcharassaeng, J. Kim, J.L. Lozada and C.J. Goodacre, 2002. Factors affecting the survival of implants placed in grafted maxillary sinuses: A clinical report. J. Prosthet. Dent., 87: 485-489.

Kapur, K.K., N.R. Garettt, M.O. Hamada, E.D. Roumanas and E. Freymiller et al., 1998. A randomized clinical trial comparing the efficacy of mandibular implantsupported overdentures and conventional dentures in diabetic patients. Part I: Methodology and clinical outcome. J. Prosthet. Dent., 79: 555-569.

Lang, N., U. Bragger, C. Hammerle and F. Sutter, 1994. Immediate transmucosal implants using the principle of guided tissue regeneration. Rational clinical procedures and 30 month results. Clin. Oral. Implants. Res., 5: 154-163.

Lekholm, U. and G.A. Zarb, 1985. Patient Selection. In: Tissue Integrated Prostheses: Osseointegration in Clinical Dentistry, Branemark, P.I., C.A. Zarb and T. Albrektsson (Eds.). Quintessence Publishing, Chicago.

McMahon, M.M. and B.R. Bristrian, 1995. Host defenses and susceptibility in patients with diabetes mellitus. Infect. Dis. Clin. North Am., 9: 1-10.

Mealey, B.L., 1998. Impact of advances in diabetes care on dental treatment of the diabetic patient. Compend. Contin. Educ. Dent., 19: 41-44.

Mealey, B.L., 1999. Diabetes Mellitus. In: Periodontal Medicine, Rose, L.F., R.J. Genco, B.L. Mealey and D.W. Cohen (Eds.). BC Decker, Inc. Publishers, Toronto.

Morris, H.F., S. Ochi and S. Winkler, 2000. Implant survival in patients with type 2 diabetes: Placement to 36 months. Ann. Periodontol., 5: 157-165.

Olson, J.W., A.F. Schernoff, J.L. Tarlow, J.A. Colwell, J.P. Scheetz and S.F. Bingham, 2000. Dental endosseous implant assessment in a type 2 diabetic population: A prospective study. Int. J. Oral Maxillofac Implants, 15: 811-818.

Ozawa, S., T. Ogawa, K. Iida, C. Sukotjo, H. Hasegawa, R.D. Nishimura and I. Nishimura, 2002. Ovariectomy hinders the early stage of bone-implant integration: Histomorphometric, biomechanical and molecular analyses. Bone, 30: 137-143. 
Pearl, S.H. and I.O. Kanat, 1988. Diabetes and healing: A review of the literature. J. Foot Surg., 27: 268-270.

Peled, M., L. Ardekian, N. Tagger-Green, Z. Gutmacher and E.E. Machtei, 2003. Dental implants in patients with type 2 diabetes mellitus: A clinical study. Implant Dent., 12: 116-122.

Penarrocha-Diago, M., C. Carrillo-Garcia, A. BoronatLopez and B. Garcia-Mira, 2008. Comparative study of wide-diameter implants placed after dental extraction and implants positioned in mature bone for molar replacement. Int. J. Oral Maxillofac Implants, 23: 497-501.

Rosenquist, B. and B. Grenthe, 1996. Immediate placement of iimplants into extraction sockets implant servival. Int. J. Oral. Maxillofac. Implants, 11: 205-209.

Takeshita, F., K. Murai, Y. Ayukawa and T. Suetsugu, 1997. Effects of aging on titanium implants inserted into the tibiae of female rats using light microscopy, SEM and image processing. J. Biomed. Mater. Res., 34: $1-8$.

Tawil, G., R. Younan, P. Azar and G. Sleilati, 2008. Conventional and advanced implant treatment in the type II diabetic patient: Surgical protocol and longterm clinical results. Int. J. Oral Maxillofac Implants, 23: 744-752.
Tervonen, T. and K. Karjalainen, 1997. Periodontal disease related to diabetic status: A pilot study of the response to periodontal therapy in type I diabetes. J. Clin. Periodontol., 24: 505-510.

UKPDS., 1998. Intensive blood glucose control with sulphonylureas or insulin compared with conventional treatment and risk of complications in patients with type 2 diabetes (UKPDS 33). Lancet, 352: 837-853.

Van Steenberghe, D., R. Jacobs, M. Desnyder, G. Maffei and M. Quirynen, 2002. The relative impact of local and endogenous patientrelated factors on implant failure up to the abutment stage. Clin. Oral Implants Res., 13: 617-622.

Westfelt, E., H. Rylander, G. Blohme, P. Jonasson and J. Lindhe, 1996. The effect of periodontal therapy in diabetics: Results after 5 years. J. Clin. Periodontol., 23: 92-100.

Yukna, R.A., 1991. Clinical comparison of hydroxyapatitecoated titanium dental implants placed in fresh extraction sockets and healed sites. J. Periodontol., 62: $468-472$ 